\title{
Possible treatment with Second Generation Antipsychotic as Supplementary Management to Treatment-Resistant Obsessive Compulsive Disorder, a Pilot Study
}

\author{
Saeed Shoja Shafti* \\ Professor of Psychiatry, University of Social Welfare and Rehabilitation Sciences (USWR), Iran
}

Submission: June 08, 2018; Published: June 21, 2018

*Corresponding author: Saeed Shoja Shafti, MD , Professor of Psychiatry, University of Social Welfare and Rehabilitation Sciences (USWR), Razi Psychiatric Hospital, Tehran - Iran , Postal Code: 18669-58891, P.O. Box: 18735-569, Tel: 0098-21-33401220; Fax: 0098-21-33401604;

E-mail: ssshafti@gmail.com

Abstract

Introduction: $40 \%-60 \%$ of the patients with obsessive-compulsive disorder remain unimproved by Serotonin-Reuptake inhibitors. The objective of this study was to examine whether addition of the atypical antipsychotic, olanzapine, to serotonin reuptake inhibitor is useful for patients with OCD who do not respond to antidepressant monotherapy.

Method: Eleven patients with obsessive compulsive disorder who had not responded to at least 2 previous treatments with a serotonin reuptake inhibitor at maximum dose and duration were assigned to receive olanzapine in addition to antidepressant for 8 weeks in an open-label study. Treatment response was assessed using the Yale-Brown Obsessive-Compulsive Scale (YBOCS).

Results: six of 11 patients respond to the olanzapine addition. The mean+/-SD baseline YBOCS score of $33.45+/-4.47$ dropped to a mean of $25+/-5.98$ at endpoint with a mean reduction of $24.56 \%$.

Conclusion: Treatment-refractory OCD Patients may benefit from addition of olanzapine to ongoing antidepressant therapy.

\section{Introduction}

Serotonin Reuptake Inhibitors (SRI) is the most effectual drug treatment accessible for obsessive-compulsive disorder (OCD) [1]. Clomipramine, citalopram, fluoxetine, fluvoxamine, paroxetine, and sertraline have been proved to be effective against obsessive and compulsive symptoms independent of their antidepressant activity [2-4]. Nevertheless, 50\%-60\% of patients with OCD fail to respond to a single trial of an SRI, and $20-40 \%$ does not respond sufficiently after several medication trials [1]. Moreover, although the selective serotonin reuptake inhibitors (SSRIs) are generally considered to be secure and well tolerated, still a proportion of subjects do experience intolerable side effects and discontinue treatment prematurely. Also, No single drug acting on different neurotransmitter systems has yet proved an absolute efficacy against obsessive-compulsive symptoms.

Therapeutic strategies in these resistant cases usually consist of augmentation therapies with, tryptophan, buspirone, clonazepam and lithium or the addition of antipsychotic drugs. But the final results with these tactics were not encouraging so far and have remained somewhat experimental than crucial. The addition of low-dose antipsychotics to standard antidepressant treatment has shown to be effective in some cases, but extrapyramidal side effects have limited the use of typical antipsychotics. Therefore treatment with atypical antipsychotic that shows fewer extrapyramidal symptoms might be a useful alternative for treatment-refractory OCD patients. Beneficial effects of adding risperidone to SSRIs has been observed in some cases of treatment-resistant obsessive-compulsive disorder [5,6]. In prior reports (four open and one double-blind studies) positive results with the addition of olanzapine to the regular antidepressant treatment of the patients [7-11] have been displayed. In the present study a new trial with olanzapine has been performed in a non-western patient population with treatment-resistant OCD.

\section{Method:}

Eleven female outpatients, after full explanation of the procedure for them and obtaining assigned informed consent, entered the study. The mean +/- SD age of the subjects was 
39.2+/- 9.08 years. Patients were diagnosed as OCD according to the DSM-TR criteria. Inclusion criteria in the present study consisted:1) OCD symptoms of at least 3 years duration and 2) a score on the YBOCS [12] of at least 18. The subject's mean +/- SD baseline score on the YBOCS was $33.45+/-4.47$ and the mean duration of illness was $16.3+/-7.35$ years. All of the patients had both obsessions and compulsions.

All patients failed at least 2 adequate treatments with an SRI at maximum dose (clomipramine $250 \mathrm{mg} /$ day, fluvoxamine $300 \mathrm{mg} /$ day, fluoxetine $80 \mathrm{mg} /$ day, sertraline $200 \mathrm{mg} /$ day, citalopram $80 \mathrm{mg} /$ day) and enough duration (12 weeks). Failure was defined as a less than $25 \%$ improvement on the YBOCS.

In an 8-week trial, all patients continued to take their current SRI at the maximum dose during trial. Four patients received clomipramine $(250 \mathrm{mg} /$ day $)$, three patients received fluvoxamine (300 mg/day), two patients received fluoxetine (80 $\mathrm{mg} /$ day), one patient received sertraline (200 mg/day) and one patient received citalopram ( $80 \mathrm{mg} /$ day). Olanzapine (generic form tablets) addition was initiated at a dose of $2.5 \mathrm{mg} /$ day and then increased by $2.5 \mathrm{mg}$ increments in weekly meetings, to a maximum of $10 \mathrm{mg}$ by week4, and then this dose was held constant up to the end of the assessment. No other psychotropic drug or psychosocial intervention was permitted during the evaluation. Subjects were seen by the same trained assessor at baseline (week 0) and at the end of weeks 4 and 8 at which times clinical response and adverse events were evaluated. The assessor was not blind to the treatment and its goals. The primary efficacy parameter was YBOCS score [12]. Full response to treatment was prospectively defined as at least $50 \%$ decrease in YBOCS score and partial response as at least $25 \%$ decrease in YBOCS score from beginning. Adverse events were assessed at each visit by means of patients' spontaneous reports and clinical examination by psychiatrist.

\section{Results}

Two patients were full responders with a mean decrease of $51 \%$ in YBOCS score. Four patients were partial responders with at least a $25 \%$ decrease. Five patients experienced no change in their obsessive-compulsive symptoms (Table 1) (Figure 1). In those who benefited from the treatment, improvement started within the first two weeks of olanzapine addition. In general patients mean YBOCS score decreased significantly (by 24.56\%) from baseline to endpoint $(t=4.23, d f=10, p<0.002)$ (Figure 2 ).

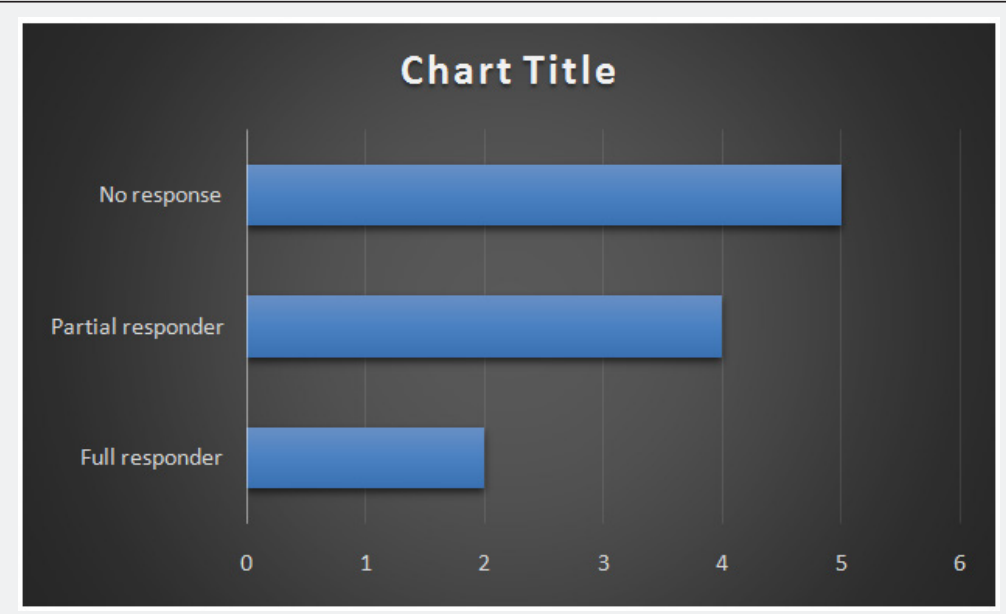

Figure 1: Response of treatment-refractory OCD cases.

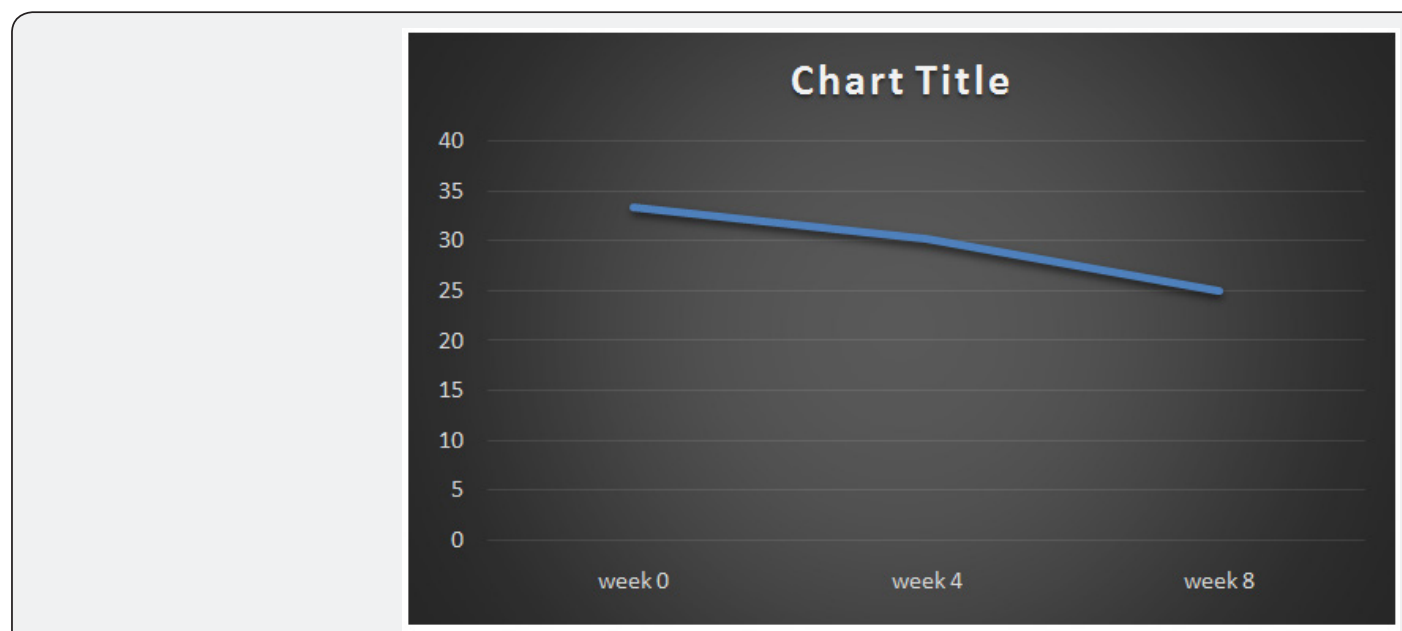

Figure 2: Decrease of YBOCD between baseline and week 8. 
Table 1: Participants' Characteristics and Outcome.

\begin{tabular}{|c|c|c|c|c|c|c|c|c|c|c|c|c|}
\hline Patient & Age & & Duration & & Comorbid & Current & Daily & YBOCS & YBOCS & $\%$ & & \\
\hline No. & (y) & Sex & $\begin{array}{c}\text { of } \\
\mathrm{OCD}(\mathrm{y})\end{array}$ & Symptoms & Diagnosis & SRI & $\begin{array}{l}\text { Dose } \\
\text { (mg) }\end{array}$ & (Baseline) & (Endpoint) & Change & $\mathbf{t}$ & Value \\
\hline 1 & 42 & $\mathrm{~F}$ & 10 & contamination & OCPD & Fluoxetine & 80 & 39 & 19 & 51.28 & & \\
\hline 2 & 38 & $\mathrm{~F}$ & 20 & contamination & None & Fluoxetine & 80 & 32 & 24 & 25 & & \\
\hline 3 & 34 & $\mathrm{~F}$ & 15 & contamination & GAD & citalopram & 80 & 31 & 28 & 9.67 & & \\
\hline 4 & 23 & $\mathrm{~F}$ & 7 & Checking & None & Sertraline & 200 & 40 & 35 & 12.5 & & \\
\hline 5 & 47 & $\mathrm{~F}$ & 15 & contamination & OCPD & Fluvoxamine & 300 & 32 & 18 & 43.75 & & \\
\hline 6 & 37 & $\mathrm{~F}$ & 11 & contamination & None & Fluvoxamine & 300 & 29 & 28 & 3.44 & & \\
\hline 7 & 50 & $\mathrm{~F}$ & 26 & Precision & None & Fluvoxamine & 300 & 37 & 18 & 51.35 & & \\
\hline 8 & 39 & $\mathrm{~F}$ & 18 & contamination & None & Clomipramine & 250 & 33 & 31 & 6.06 & & \\
\hline 9 & 28 & $\mathrm{~F}$ & 9 & Checking & OCPD & Clomipramine & 250 & 25 & 18 & 28 & & \\
\hline 10 & 54 & $\mathrm{~F}$ & 31 & contamination & None & Clomipramine & 250 & 33 & 29 & 12.12 & & \\
\hline 11 & 40 & $\mathrm{~F}$ & 18 & contamination & None & Clomipramine & 250 & 37 & 27 & 27.02 & & \\
\hline Mean & 39.2 & & 16.3 & & & & & 33.45 & 25 & 24.56 & 4.23 & 0.002 \\
\hline SD & 9.08 & & 7.35 & & & & & 4.47 & 5.98 & & & \\
\hline
\end{tabular}

Abbreviations: GAD: Generalized anxiety disorder; YBOCS: Yale-Brown Obsessive Compulsive Scale; OCD: Obsessive-compulsive disorder; OCPD: Obsessive-compulsive personality disorder.

The most common adverse effects of olanzapine in our samples were weight gain (2), somnolence (3), dizziness (2), dyspepsia (2), tremor (1), and constipation (1). Since the side effects were mild and well tolerated, no one dropped out owing to medication intolerance.

\section{Discussion}

This study provides additional evidence that addition of olanzapine to ongoing SRI treatment may be efficacious for therapy-refractory OCD patients. There are, however, limitations to the data presented due to the small sample size and openlabel design. In all, the results of our study are consistent with the findings of previous addition trials with risperidone and olanzapine [5-11]. Supplementing SRIs with atypical antipsychotics shows benefits, but the main problem here is that there is some inconsistency in the definition of treatment refractoriness. Most studies included patients who had failed to respond to only one SRI trial. They should rather be qualified as treatment resistant. The dilemma of deficient response is an area under discussion and merits further investigation. Furthermore, a clear criteria for no response needs to be agreed upon because frequently the standards for response rates differ to a great extent. For example, Weiss et al. [7] used a cutoff of 50\% decrease in YBOCS score as responders, while Francobanderia [10] chose a cutoff of 25\%. McDougle et al. [6], on the other hand, used a more restrictive criterion with a cutoff of 35\% for YBOCS decrease and a final score of 16 on the YBOCS in combination with a final Clinical Global Impressions scale rating of much improved or very much improved. Such differences nullify the comparison of effect sizes between different studies.

Atypical antipsychotics may enhance the action of SRIs through serotonin receptor blockade. The broader range of effective treatment with the addition of atypical antipsychotics may be due to a D2 blockade, or a combined serotonergicdopaminergic blockade, particularly 5-HT2A and D2 antagonism [5]. Anyhow, addition of atypical antipsychotics to SRIs seems a promising pharmacotherapy intervention for treatment refractory OCD patients. No doubt, further studies as regards the mechanism of action of these augmentative strategies for OCD are warranted.

\section{Conclusion}

Treatment-refractory OCD Patients may benefit from addition of olanzapine to ongoing antidepressant therapy.

\section{References}

1. Fienberg NA, Bullock T, Montgomery DB, Montgomery SA (1992) Serotonin reuptake inhibitors are the treatment of choice in obsessivecompulsive disorder. Int Clin Psychopharmacol (suppl 1): 43.

2. Mcdougle CJ, Goodman WK, Price LH (1993) The pharmacotherapy of obsessive-compulsive disorder. Pharmopsychiatry 26: 24-29

3. Hollander E, Kaplan A, Allen A, Cartwright C (2000) Pharmacotherapy for obsessive-compulsive disorder. Psychiatric Clin North AM 23(3):643-656.

4. Goodman WK, Price LH, Rasmussen SA, et al. (1989) Efficacy of fluvoxamine in obsessive-compulsive disorder: a comparison with placebo. Arch Gen Psychiatry 46(1): 36-44 
5. McDougle CJ, Fleischmann RL, Epperson CN, et al. (1995) Risperidone addition in fluvoxamine-refractory obsessive-compulsive disorder: three cases. J Clin Psychiatry 56(11): 526-528

6. McDougle CJ, Epperson CN, Pelton GH, et al. (2000) A double-blind, placebo-controlled study of resperidone addition in serotonin reuptake inhibitor-refractory obsessive-compulsive disorder. Arch Gen Psychiatry 57(8): 794-801

7. Weiss El, Potenza MN, McDougle CJ , et al. (1999) Olanzapine addition in obsessive-compulsive disorder refractory to selective serotonin reuptake inhibitors: an open-label case series. J Clin Psychiatry 60(8):524-527.

8. Koran LM, Ringold AL, Elliot MA (2000) Olanzapine augmentation for treatment-resistant obsessive-compulsive disorder. J Clin Psychiatry 61(7): 514-517
9. Bogetto F, Bellino S, Vaschetto P, et al. (2000) Olanzapine augmentation of fluvoxamine-refrectory obsessive-compulsive disorder (OCD): a 12week open trial. Psychiatry Res 96(2): 91-98

10. Francobandiera G (2001) Olanzapine augmentation of serotonin uptake inhibitors in obsessive-compulsive disorder: an open study. Can J Psychiatry 46(4): 356-358

11. Bystrisky A (2001) Augmentation of SSRI response in refractory OCD using adjunct olanzapine: a placebo-controlled trial. In: New Research Abstracts of the $154^{\text {th }}$ Annual Meeting of the American Psychiatric Association New Orleans, Louisiana.

12. Goodman WK, Price LH, Rasmussen SA, et al. (1989) The Yale-Brown Obsessive Compulsive Scale, 1: Development, use, and reliability. Arch Gen Psychiatry 46(11): 1006-1011

\section{Your next submission with Juniper Publishers will reach you the below assets}

- Quality Editorial service

- Swift Peer Review

- Reprints availability

- E-prints Service

- Manuscript Podcast for convenient understanding

- Global attainment for your research

- Manuscript accessibility in different formats ( Pdf, E-pub, Full Text, Audio)

- Unceasing customer service

Track the below URL for one-step submission https://juniperpublishers.com/online-submission.php 